\title{
Current Insights on Early Life Nutrition and Prevention of Allergy
}

\section{Giuliana Ferrante, Maurizio Carta, Claudio Montante, Veronica Notarbartolo, Giovanni Corsello and Mario Giuffrè *}

Dipartimento di Promozione della Salute, Materno-Infantile, Medicina Interna e Specialistica di Eccellenza "G. D'Alessandro," Università degli Studi di Palermo, Palermo, Italy

The incidence of allergic diseases in childhood appears to have significantly increased over the last decades. Since environmental factors, including diet, have been thought to play a significant role in the development of these diseases, there is great interest in identifying prevention strategies related to early nutritional interventions. Breastfeeding is critical for the immune development of newborns and infants through immune-modulating properties and it impacts the establishment of a healthy gut microbiota. However, the evidence for a protective role of breastfeeding against the development of food allergy in childhood is controversial, and there is little evidence to support the benefits of an antigen avoidance diet during lactation. Although it is not possible to draw a definitive conclusion about the protective role of breast milk against allergic diseases, exclusive breastfeeding is still recommended throughout the

OPEN ACCESS

Edited by:

Diego G. Peroni,

University of Pisa, Italy

Reviewed by:

Carina Venter,

University of Colorado, United States Marion Elizabeth Groetch, Icahn School of Medicine at Mount Sinai, United States

*Correspondence: Mario Giuffrè mario.giuffre@unipa.it

Specialty section:

This article was submitted to Pediatric Immunology,

a section of the journal

Frontiers in Pediatrics

Received: 22 April 2020

Accepted: 29 June 2020

Published: 06 August 2020

Citation:

Ferrante G, Carta M, Montante C Notarbartolo V, Corsello G and Giuffrè M (2020) Current Insights on Early Life Nutrition and Prevention of Allergy. Front. Pediatr. 8:448. doi: 10.3389/fped.2020.00448 first 6 months of life due to associated health benefits. Furthermore, recommendations regarding complementary feeding in infancy have been significantly modified over the last few decades. Several studies have shown that delayed exposure to allergenic foods does not have a role in allergy prevention and recent guidelines recommend against delaying the introduction of complementary foods after 6 months of age, both in high- and low-risk infants. However, trials investigating this dietary approach have reported equivocal results so far. This review summarizes the available high-quality evidence regarding the efficacy of the principal dietary interventions proposed in early life to prevent allergic diseases in children.

Keywords: nutrition, allergy, prevention, breastfeeding, microbiota, diet, complementary feeding

\section{INTRODUCTION}

Environmental exposures, such as nutritional intake during the critical stages of pregnancy and in the early postnatal period, play a significant role in the development of infant immune system and it has been suspected that may also be involved in the origin of childhood atopic diseases (1).

Many studies have investigated the association between maternal diet and the development of childhood allergic diseases, however, to date, the results have been largely inconclusive and controversial (2). Exclusive breastfeeding is recommended throughout the first 6 months of life, due to associated health benefits, but it is also apparent that breastfeeding should be continued beyond 6 months after the introduction of complementary foods (CF). Duration of breastfeeding rather than exclusivity may be important in prevention of allergic diseases. Nonetheless, while the evidence for a protective role of breastfeeding against the development of food allergy is controversial, the recommendations regarding introduction of complementary foods in infancy have significantly changed over the last decades. 
This mini review summarizes the current high-quality evidence regarding the principal early life dietary interventions in preventing allergic diseases in children, particularly in regard to maternal diet during pregnancy, breastfeeding, and introduction of complementary foods.

\section{MATERNAL DIET DURING PREGNANCY: DOES IT INFLUENCE THE RISK OF ALLERGIC DISEASES IN OFFSPRING?}

Maternal diet during pregnancy represents the earliest nutritional exposure to allergens for the fetus. Most studies to date have demonstrated an equivocal correlation between maternal diet during pregnancy and the development of childhood allergic diseases. A Cochrane systematic review did not support allergen avoidance or nutrient supplementation during pregnancy as a means to prevent allergic diseases in offspring (3). However, evidence from mother consumption of peanut and tree nuts suggests that fetal allergen exposure through maternal diet may actually increase tolerance and reduce risk of developing these childhood food allergies (4). Therefore, further studies are needed to elucidate the role of maternal nutrition in the development of food allergies in offspring.

\section{Fatty Acids}

A causal relationship between early maternal consumption of polyunsaturated fatty acids (PUFAs) and childhood allergic diseases is debated (5). The T-helper shift from type 1 to type 2 may derive from a higher $n-6: n-3$ fatty acids ratio during pregnancy, leading to an increased risk of allergic rhinitis in offspring (6). It is thought that N-3 PUFAs probably limit cytokine cascade (7), decrease n-6 PUFA inflammatory effects, regulate $\mathrm{T}$ cell function (cell membrane fluidity, signaling, and gene transcription), and promote long-term effects through epigenetic mechanisms (8). Therefore, daily maternal supplementation of n-3 PUFAs could reduce the risk of food allergies and IgE-associated eczema in infants with a family history of allergy (9). However, findings about the role of $n-3$ PUFA supplementation in pregnancy for reducing the overall incidence of allergic outcomes in offspring are still insufficient.

\section{Antioxidants}

Antioxidants (i.e., vitamin E, flavonoids, selenium, and copper) intake during pregnancy may be beneficial, as they have immunomodulatory properties and could play a role on fetal lung development and on respiratory health later in life, thus reducing the risk of wheezing (10).

\section{Vitamin D}

The association between vitamin D status of pregnant women and the development of atopic diseases in childhood is not clear. For this reason, prenatal vitamin D supplementation for the prevention of allergic diseases in offspring is not currently recommended. We know 25-hydroxyvitamin D3 levels in cord blood are directly associated with lower mononuclear cell cytokine responses to allergens and reduced risk of eczema in the first 12 months of life (11). In addition, higher vitamin D intake during pregnancy has been associated with lower risk of wheezing and eczema in offspring at 16-24 months of age (12). However, follow-up of the same cohort showed an increased risk of eczema later in life (13). The immunomodulatory mechanism of vitamin D seems to have an influence on Th2 cells differentiation, but its benefits are still unclear and the literature is conflicting (14).

\section{Foods}

A recent prospective birth cohort study showed an association between prenatal maternal intake of certain foods and the risk of allergic diseases in offspring by the age of 3 years (10). Namely, consumption of green vegetables, eggs, and grains were found to play a protective role against respiratory allergic diseases, whereas higher meat intake in the preconception period was positively associated with an increased risk of wheezing, allergic rhinitis, and eczema. In a previous prospective cohort study, a diet rich in vegetables during pregnancy has been associated with reduced risk of childhood asthma in offspring (15). A systematic review and meta-analysis concluded that maternal fish consumption during pregnancy did not reduce the risk of allergic outcome in offspring (16).

\section{BREASTFEEDING: DOES HUMAN MILK PLAY A PROTECTIVE ROLE?}

Current guidelines recommend human milk (HM) as the "gold standard" for infant nutrition (17). Breastfeeding prolongs the interaction with the mother's immune system and may influence oral tolerance and the risk of allergies in childhood. Pivotal studies clearly confirm the relevant role of breastfeeding for short-term infant health (e.g., growth, immune function, protection against infections) as well as for potential long-term advantages (e.g., neurocognitive development, prevention of malignancies, and non-communicable diseases) (18). Nevertheless, the evidence for the role of HM for the prevention of allergic diseases remains limited and controversial. This is due to variable definitions of allergic outcomes and to the lack of randomized controlled trials with detailed information about the maternal diet in breastfeeding. While many studies emphasize a protective effect, others even suspect HM may promote allergies (19). The balance between oral tolerance and skin sensitization may affect food allergy risk among infants with eczema: additional evidence suggests that colostrum has a prophylactic role in maintaining oral tolerance, but in case of severe cutaneous barrier dysfunction the protective effect of prolonged breastfeeding is lost (20). Early oral exposure to aeroallergens through HM intake could increase the risk of sensitization in offspring (21). On the other hand, exclusive breastfeeding seems to reduce the incidence of eczema in the first 2 years of life and the risk of asthma in the first 5 years $(22,23)$, or even 10 years with weaker evidence (24).

Several reasonable explanations account for HM protective effects on allergy susceptibility in children: stimulation of immune development (direct interactions with infant immune cells), epigenetic actions (DNA methylation, and non-coding RNAs), modulation of gut microbiota. 
Breast milk is a living tissue and various bioactive factors appear to be involved. For instance, TGF- $\beta$ is a regulatory cytokine crucial for long-lasting Treg-mediated food tolerance (25). Maternal antigen immune complexes (IgG-IC) in breast milk may interact with the neonatal crystallizable fragment receptor $(\mathrm{FcRn})$ on infant dendritic cells (26), favoring oral tolerance. In addition, breast milk contains up to $10^{5}$ bacterial cells/ml: HM microbiota plays a role in bacterial colonization of the infant intestinal tract that could contribute to modulate allergy susceptibility early and later in life. Finally, human milk oligosaccharides (HMOs) can play a key role in neonatal mucosal and systemic immunity. HMOs represent an antimicrobial barrier acting as soluble decoy receptors that block adhesion of various pathogens, promote intestinal development, and stimulate immunomodulation acting as signal molecules for the host cells. Some HMOs have been proven to play a crucial role in shaping gut microbiota and regulating early life immune development, but the precise mechanism is currently unknown. Furthermore, specific HMOs profiles have been associated with lower risk of cow's milk allergy (27).

Different formulas are available for newborns and infants who cannot be breastfed. Among them, hydrolyzed formulas have been specifically proposed for infants at risk of allergies; however, their role in allergy prevention is still under debate (28).

\section{COMPLEMENTARY FEEDING: DOES TIMING OF FOOD INTRODUCTION INFLUENCE THE RISK OF ALLERGIES?}

In past years, it has been traditionally recommended to delay the introduction of foods recognized as potentially allergenic, based on the theory that the gut structural and functional immaturity and increased permeability determines an increased risk of allergic sensitization (29). Nevertheless, early exposure to these allergens may be critical to achieve food tolerance, which is an antigen-driven process as suggested by animal models (30). According to the so-called "dual-allergen exposure hypothesis," oral administration of food allergens favors the establishment of tolerance via the expansion of Th1 and Treg populations, whereas exposure to food allergens through skin barrier disruptions favors sensitization via Th2 switch and cytokines production (29).

Current evidence suggests that oral allergen exposure may start at 4 months onwards, although proper timing of this "critical window" is still not clear (31).

In 2016, the Enquiring About Tolerance trial showed that, in a general population of exclusively breastfed infants, the early (i.e., between 3 and 6 months of age) introduction of potentially allergenic foods (cow's milk, cooked egg, peanut, fish, wheat, and sesame) was effective for prevention of food allergy (32). In particular, while the incidence of food allergy at 3 years of age was not significantly different between the early introduction group compared to the control group in the intention-to-treat analysis, the per-protocol analysis showed a significant reduction of overall incidence of food allergy, peanut allergy, and egg allergy in the early introduction group. However, the high rate of non-adherence in the early introduction group (68.1\%) limits the reliability of the study results. Results from the Learning Early About Peanut Allergy trial suggested that peanut should be introduced between 4 and 11 months in infants at high risk for allergy (33). According to a recent systematic review, this practice may reduce the risk of peanut allergy, with the strongest evidence supporting a benefit to high risk infants (i.e., with severe atopic dermatitis or egg allergy) but it is also applicable to infants at lower risk (34). In addition to these findings, there is limited high quality evidence suggesting the lack of a relationship between consumption of peanut during weaning and the risk of atopic dermatitis/eczema and asthma, while not enough evidence supports the causal relationship between consuming peanut and developing allergic rhinitis at 2, 5, or 6 years of age (34).

Many studies addressing the effect of egg introduction on the risk of developing allergy, have provided conflicting results. This is likely due to unaccounted variables from different study populations, as well as variations in dose and form of the eggs used (raw or cooked) (35-39). However, a recent systematic review provided moderate evidence that introducing egg at 4-6 months of age may reduce the risk of developing egg allergy (34). In the same study, limited evidence showed the lack of association between the timing of egg introduction and the development of atopic dermatitis/eczema and asthma, while not enough evidence supported a relationship with risk of allergic rhinitis in the first 5 years of life (34).

Previous observational studies have also investigated the effect of the timing of fish introduction on the risk of allergic diseases $(40,41)$. A recent systematic review provided limited evidence to suggest that the introduction of fish between 3 and 8 months of life may lower the risk of atopic dermatitis/eczema (34). However, at present there is not enough evidence of a link between fish consumption and food allergy, asthma, or allergic rhinitis (42).

With regard to cow-milk, while previous observational studies reported conflicting results on the risk of cow's milk allergy $(43,44)$, more recently a randomized clinical trial demonstrated that the risk of sensitization to cow's milk as well as the risk of immediate food allergy were decreased by avoiding supplementation with cow's milk formula for at least the first 3 days of life (45). In addition, a recent systematic review provided limited high quality evidence suggesting the lack of a relationship between age of introduction and risk of food allergy and atopic dermatitis/eczema. However, there was not enough evidence to support an association between cow's milk formula supplementation and the development of asthma and allergic rhinitis (34).

Overall, these findings suggest that there is not a clear optimal timing of introduction of potential allergenic foods for preventing allergic diseases, either for infants in the general population or for high-risk infants (Table 1). The latest recommendations issued by the World Health Organization (46), the American Academy of Pediatrics (22), the European Academy of Allergy and Clinical Immunology (47), the European Society for Paediatric Gastroenterology Hepatology and Nutrition (30), the European Food Safety Authority (48), and the British Society for Allergy, and Clinical Immunology (49) have all emphasized the lack of scientific data to support the introduction of the commonly acknowledged allergenic foods 
TABLE 1 | Timing of introduction of CF and risk of allergic diseases in childhood.

\begin{tabular}{|c|c|c|c|c|}
\hline Type of CF & \multicolumn{4}{|c|}{ Allergic disease } \\
\hline Cow-milk products & $\begin{array}{l}\text { Introduction within the first few days } \\
\text { of life is associated with an increased } \\
\text { risk of developing cow's milk allergy } \\
\left(44^{\S}\right) \\
\text { Introduction within the first } 2 \text { weeks of } \\
\text { life reduces the risk of cow's milk } \\
\text { allergy, whereas introduction between } \\
4 \text { to } 6 \text { months increased this risk } \\
(45 \S) \\
\text { Avoiding supplementation with cow's } \\
\text { milk formula for at least } 3 \text { days of life } \\
\text { decreases the risk of cow's milk } \\
\left.\text { allergy ( } 46^{\star}\right) \\
\text { No relationship between age of } \\
\text { introduction and risk of food allergy } \\
\text { (35 \#) }\end{array}$ & $\begin{array}{l}\text { No relationship between age of } \\
\text { introduction and risk of atopic } \\
\text { dermatitis/eczema (35\#) }\end{array}$ & $\begin{array}{l}\text { No relationship between age of } \\
\text { introduction and risk of asthma } \\
\text { (35\#) }\end{array}$ & $\begin{array}{l}\text { No relationship between age of } \\
\text { introduction and risk of allergic } \\
\text { rhinitis (35\#) }\end{array}$ \\
\hline
\end{tabular}

§observational study.

*randomized control study.

\#systematic review.

before 4 months of age, but also the absence of evidence to justify a delayed introduction of CF after 6 months of age to prevent allergy, both in high and low-risk infants (Supplementary Table 1).

\section{DIET-INDUCED CHANGES IN GUT MICROBIOTA: DO THEY INFLUENCE ALLERGY RISK?}

\section{Pregnancy}

Evidence suggests that early life gut microbial dysbiosis precedes atopy development and that the gut microbiota of allergic children may show a depleted diversity $(50,51)$. In particular, a reduction of certain bacteria (e.g., Bifidobacterium, Akkermansia, and Faecalibacterium) could drive CD4+ cell dysfunction, thereby increasing the risk of atopic diseases (52). It has been recently suggested that diet during pregnancy may indirectly affect tolerance acting on the microbiota diversity. In particular, fiber consumption appears to lead to changes in the maternal gut microbiota metabolism by increasing the production of short-chain fatty acids (SCFAs), which represent the first metabolites of gut commensal microbiota. Therefore, SCFAs that cross the placenta, influence gene transcription in fetal lung and enhance oral tolerance to allergens by promoting epithelial integrity, $\mathrm{T}$ regulatory (Treg) cell differentiation, and IgA release from plasma cells, with long-lasting effects on health (53). Furthermore, it seems that 


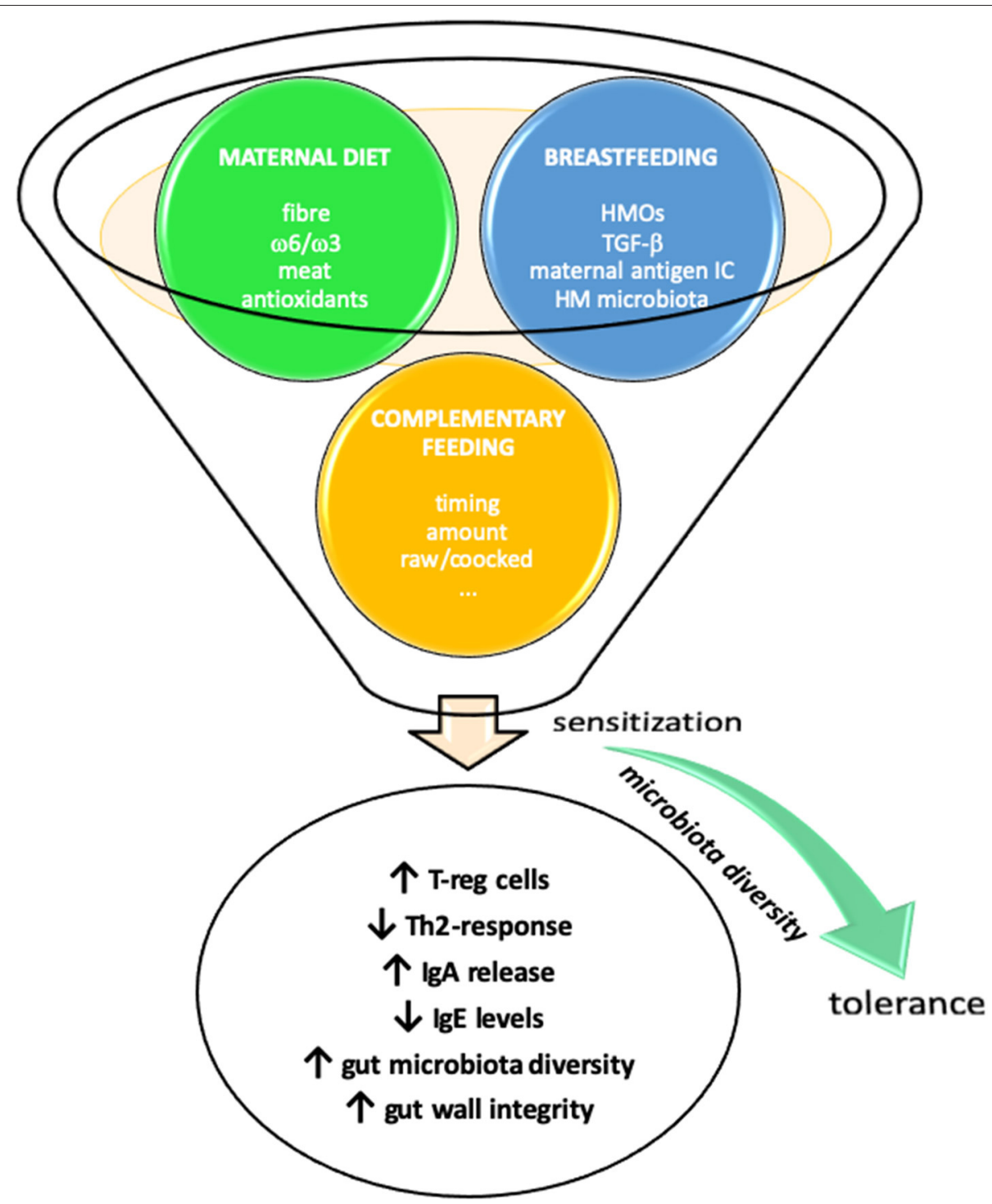

FIGURE 1 | Early life nutrition and prevention of allergic diseases. Maternal diet during pregnancy and lactation and introduction of complementary foods may influence susceptibility to allergic diseases through several diverse mechanisms.

fetal Treg cells may be informed by substantial numbers of maternal cells crossing the placenta and inducing antigenspecific tolerance. In utero transfer of microbial antigens during fetal development would enable a balanced immune response of the newborn to the rapidly developing microbiota postpartum (54).

\section{Early Life}

In recent years there has been increased scientific interest and studies into the role of CF introduction to the infant diet and the risk of allergy. Investigations have sought to determine if there is a cause-effect relationship between diet-induced changes of infant's microbiota and the development of allergic diseases.

Indeed, during weaning, a dramatic change of intestinal microbiota occurs, which is reflected in the transitioning nature of stool composition (55). Thus, it has been suggested that the resident microbiota of the gastrointestinal tract, interacting with solid foods, may be able to modulate the immune system development in early life (56).

In breastfed infants, a rapid rise in the number of Enterobacteria and Enterococci has been demonstrated (57), along with an increased amount of Bifidobacterium and Lactobacillus spp. (58). Conversely, in formula-fed infants, a greater abundance of Bacteroides and Clostridium spp. has been observed, this difference could have implications for the subsequent development of atopic diseases $(57,58)$. The introduction of CF drives the gut microbiota composition favoring bacteria within the Bacteroidetes and Firmicutes phyla (58). Most of the reported changes in gut microbiota appear to occur after weaning, from age 9-18 months until the 3rd year of life, when the microbiota stabilizes resembling the adult one (59). Therefore, the window of opportunity for modulating the 
intestinal microbiota composition extends up to the first 2 years of life, conversely any dysbiosis in this period could determine an abnormal immune system activation, possibly leading to the development of pathological conditions such as allergy (56).

It has been hypothesized that a more diverse diet leads to a more diverse gut microbiota, which may improve the gut wall integrity and the immune system regulation, supporting the expansion of Treg cells (60), and suppressing IgE levels (61). Indeed, a lower microbiota diversity with an increased number of Firmicutes vs. of Bacteroidetes, has been observed in children with food sensitization (62). An increased microbial diversity along with the relative abundance of certain bacteria, such as Lactobacillus spp. (63), has been correlated with a lower risk of IgE-associated allergic diseases, namely atopic dermatitis and wheezing, through a decreasing Th2-mediated response (64). No significant association between the diversity of complementary foods and allergic rhinitis has been found so far (65).

According to these findings, early infancy does appear as a window of opportunity during which diet intervention may shape the risk of allergic diseases by modulating the composition of the gut microbiota (60). In this context, it has been demonstrated in a murine model that dietary fiber intake leads to marked suppression of the induction of airway allergic disease, by enhancing Treg cell number and function (66). A possible explanation is that SCFAs, which would seem to reduce airway inflammation even in human models, are produced by the microbiota through the metabolism of dietary fibers (65).

A protective effect against the risk of allergic diseases might be also derived from the supplementation with prebiotics which can indirectly promote the production of anti-inflammatory cytokines by increasing the number of Lactobacillus and Bifidobacterium spp. (67). Finally, it has been suggested that adequate levels of vitamin D during the 1st year of life may lower the risk of developing food allergies, by modulating the gut microbiota composition (68), with increased Lachnospiraceae and reduced Lactococcus spp. (69).

Overall, these studies have contributed to deepening our knowledge about gut microbiota diversity and species-specific changes. Unfortunately, however, how to manipulate the intestinal microbiota for the prevention of allergic diseases is still a matter of debate.

\section{CONCLUSIONS}

The link between early dietary factors and the development of allergy later in life is still not clear. Many dietary factors, from prenatal life through infancy, have been proposed to influence

\section{REFERENCES}

1. Duijts L, Reiss IK, Brusselle G, de Jongste JC. Early origins of chronic obstructive lung diseases across the life course. Eur J Epidemiol. (2014) 29:871-85. doi: 10.1007/s10654-014-9981-5

2. Garcia-Larsen V, Ierodiakonou D, Jarrold K, Cunha S, Chivinge J, Robinson $Z$, et al. Diet during pregnancy and infancy and risk of allergic or autoimmune disease: a systematic review and meta-analysis. PLoS Med. (2018) 15:e1002507. doi: 10.1371/journal.pmed.1002507 the susceptibility to allergic diseases, by modulating the gut microbiota composition and promoting tolerance to allergens. None of these, other than early introduction of allergens, has been proven effective (Figure 1).

Current high-quality evidence for the efficacy of the principal dietary interventions demonstrates that maternal avoidance of allergenic foods during pregnancy and lactation is not effective in preventing allergic diseases. Some evidence suggests that a maternal diet rich in fibers, antioxidants, and n-3 PUFAs might promote a protective immunomodulatory role, also mediated by changes in microbiota. However, further studies are needed to elucidate the role of maternal nutrition in the development of food allergy in offspring.

Evidence for an overall protective role of breastfeeding against allergic diseases is still controversial, even though exclusive breastfeeding is recommended as the "gold standard" for infant nutrition during the first 6 months of life.

With regard to complementary feeding, there is no clear evidence to support a specific timing to the introduction of potentially allergenic foods for preventing allergic diseases, either for infants in the general population or for high-risk infants. Nonetheless, complementary feeding should not be delayed after 6 months of age, nor should breastfeeding be discontinued.

The diversity of the intestinal microbiota in early life is likely associated with a reduced risk of allergies. Indeed, it has been suggested that poor gut microbial diversity may increase the risk of developing allergic diseases. Thus, early infancy does appear as a window of opportunity during which dietary intervention may influence the risk of allergic diseases.

To better identify efficacious dietary strategies for primary prevention of allergies in childhood, future research should implement longitudinal interventional studies in cohorts of pregnant women and their offspring, as well as randomized controlled trials to clarify the potential role of complementary foods and their optimal timing of introduction.

\section{AUTHOR CONTRIBUTIONS}

GF, MC, and MG: conceptualization. GF, MC, CM, VN, and MG: writing original draft. GC and MG: review and editing. All the authors read and approved the final version of the manuscript.

\section{SUPPLEMENTARY MATERIAL}

The Supplementary Material for this article can be found online at: https://www.frontiersin.org/articles/10.3389/fped. 2020.00448/full\#supplementary-material 
5. Venter C, Meyer RW, Nwaru BI, Roduit C, Untersmayr E, Adel-Patient $\mathrm{K}$, et al. EAACI position paper: influence of dietary fatty acids on asthma, food allergy, and atopic dermatitis. Allergy. (2019) 74:142944. doi: 10.1111/all.13764

6. Nwaru BI, Erkkola M, Lumia M, Kronberg-Kippilä C, Ahonen S, Kaila M, et al. Maternal intake of fatty acids during pregnancy and allergies in the offspring. Br J Nutr. (2012) 108:720-32. doi: 10.1017/S0007114511005940

7. Dunstan JA, Mori TA, Barden A, Beilin LJ, Taylor AL, Holt PG, et al. Fish oil supplementation in pregnancy modifies neonatal allergen-specific immune responses and clinical outcomes in infants at high risk of atopy: a randomized, controlled trial. J Allergy Clin Immunol. (2003) 112:117884. doi: 10.1016/j.jaci.2003.09.009

8. Bianchi M, Alisi A, Fabrizi M, Vallone C, Ravà L, Giannico R, et al. Maternal intake of $n-3$ polyunsaturated fatty acids during pregnancy is associated with differential methylation profiles in cord blood white cells. Front Genet. (2019) 10:1050. doi: 10.3389/fgene.2019.01050

9. Bisgaard H, Stokholm J, Chawes BL, Vissing NH, Bjarnadóttir E, Schoos AM, et al. Fish oil-derived fatty acids in pregnancy and wheeze and asthma in offspring. N Engl J Med. (2016) 375:2530-9. doi: 10.1056/NEJMoa1503734

10. Baïz N, Just J, Chastang J, Forhan A, de Lauzon-Guillain B, Magnier $\mathrm{AM}$, et al. Maternal diet before and during pregnancy and risk of asthma and allergic rhinitis in children. Allergy Asthma Clin Immunol. (2019) 15:40. doi: 10.1186/s13223-019-0353-2

11. Jones AP, D’Vaz N, Meldrum S, Palmer DJ, Zhang G, Prescott SL, et al. 25hydroxyvitamin D3 status is associated with developing adaptive and innate immune responses in the first 6 months of life. Clin Exp Allergy. (2015) 45:220-31. doi: 10.1111/cea.12449

12. Miyake Y, Sasaki S, Tanaka K, Hirota Y. Dairy food, calcium and vitamin D intake in pregnancy, and wheeze and eczema in infants. Eur Respir J. (2010) 35:1228-34. doi: 10.1183/09031936.00100609

13. Miyake Y, Tanaka K, Okubo H, Sasaki S, Arakawa M. Dairy food, calcium and vitamin $\mathrm{D}$ intake and prevalence of allergic disorders in pregnant Japanese women. Int J Tuberc Lung Dis. (2012) 16:255-61. doi: 10.5588/ijtld.11.0173

14. Loo EXL, Tham EH, Phang KW, Goh A, Teoh OH, Chong YS, et al. Associations between maternal vitamin $\mathrm{D}$ levels during pregnancy and allergic outcomes in the offspring in the first 5 years of life. Pediatr Allergy Immunol. (2019) 30:117-22. doi: 10.1111/pai.12995

15. Viljoen K, Segurado R, O'Brien J, Murrin C, Mehegan J, Kelleher CC, et al. Pregnancy diet and offspring asthma risk over a 10-year period: the lifeways cross generation cohort study, Ireland. BMJ Open. (2018) 8:e017013. doi: 10.1136/bmjopen-2017-017013

16. Zhang GQ, Liu B, Li J, Liu CQ, Zhang Q, Chen JL et al. Fish intake during pregnancy or infancy and allergic outcomes in children: a systematic review and meta-analysis. Pediatr Allergy Immunol. (2017) 28:15261. doi: 10.1111/pai.12648

17. Kramer MS, Kakuma R. Optimal duration of exclusive breastfeeding. Cochrane Database Syst Rev. (2012) 2012:CD003517. doi: 10.1002/14651858.CD003517.pub2

18. Fleischer DM, Spergel JM, Assa'ad AH, Pongracic JA. Primary prevention of allergic disease through nutritional interventions. J Allergy Clin Immunol Pract. (2013) 1:29-36. doi: 10.1016/j.jaip.2012.09.003

19. Lodge CJ, Tan DJ, Lau MX, Dai X, Tham R, Lowe AJ, et al. Breastfeeding and asthma and allergies: a systematic review and meta-analysis. Acta Paediatr. (2015) 104:38-53. doi: 10.1111/apa.13132

20. Matsumoto N, Yorifuji T, Nakamura K, Ikeda M, Tsukahara H, Doi H. Breastfeeding and risk of food allergy: a nationwide birth cohort in Japan. Allergol Int. (2020) 69:91-7. doi: 10.1016/j.alit.2019.08.007

21. Baïz N, Macchiaverni P, Tulic MK, Rekima A, Annesi-Maesano I, Verhasselt V, et al. Early oral exposure to house dust mite allergen through breast milk: a potential risk factor for allergic sensitization and respiratory allergies in children. J Allergy Clin Immunol. (2017) 139:36972.e10. doi: 10.1016/j.jaci.2016.07.021

22. Greer FR, Sicherer SH, Burks AW, Committee on Nutrition; Section on Allergy and Immunology. The effects of early nutritional interventions on the development of atopic disease in infants and children: the role of maternal dietary restriction, breastfeeding, hydrolyzed formulas, and timing of introduction of allergenic complementary foods. Pediatrics. (2019) 143:e20190281. doi: 10.1542/peds.2019-0281
23. Klopp A, Vehling L, Becker AB, Subbarao P, Mandhane PJ, Turvey SE, et al. Modes of infant feeding and the risk of childhood asthma: a prospective birth cohort study. J Pediatr. (2017) 190:192-9.e2. doi: 10.1016/j.jpeds.2017.07.012

24. van Meel ER, de Jong M, Elbert NJ, den Dekker HT, Reiss IK, de Jongste JC, et al. Duration and exclusiveness of breastfeeding and school-age lung function and asthma. Ann Allergy Asthma Immunol. (2017) 119:216.e2. doi: 10.1016/j.anai.2017.05.002

25. Liu Z, Li J, Wang K, Tan Q, Tan W, Guo G. Association between TGFb1 polymorphisms and asthma susceptibility among the chinese: a meta-analysis. Genet Test Mol Biomarkers. (2018) 22:433-42. doi: 10.1089/gtmb.2017.0238

26. Ohsaki A, Venturelli N, Buccigrosso TM, Osganian SK, Lee J, Blumberg RS, et al. Maternal IgG immune complexes induce food allergen-specific tolerance in offspring. J Exp Med. (2018) 215:91-113. doi: 10.1084/jem.20171163

27. de Kivit S, Kostadinova AI, Kerperien J, Morgan ME, Muruzabal VA, Hofman GA, et al. Dietary, nondigestible oligosaccharides and Bifidobacterium breve $\mathrm{M}-16 \mathrm{~V}$ suppress allergic inflammation in intestine via targeting dendritic cell maturation. J Leukoc Biol. (2017) 102:105-15. doi: 10.1189/jlb.3A0516-236R

28. Cabana MD. The role of hydrolyzed formula in allergy prevention. Ann Nutr Metab. (2017) 70:38-45. doi: 10.1159/000460269

29. Devonshire AL, Robison RG. Prevention of food allergy. Allergy Asthma Proc. (2019) 40:450-2. doi: 10.2500/aap.2019.40.4269

30. Fewtrell M, Bronsky J, Campoy C, Domellöf M, Embleton N, Fidler Mis $\mathrm{N}$, et al. Complementary feeding: a position paper by the European society for paediatric gastroenterology, hepatology, and nutrition (ESPGHAN) committee on nutrition. J Pediatr Gastroenterol Nutr. (2017) 64:11932. doi: 10.1097/MPG.0000000000001454

31. Prescott SL, Smith P, Tang M, Palmer DJ, Sinn J, Huntley SJ, et al. The importance of early complementary feeding in the development of oral tolerance: concerns and controversies. Pediatr Allergy Immunol. (2008) 19:375-80. doi: 10.1111/j.1399-3038.2008.00718.x

32. Perkin MR, Logan K, Tseng A, Raji B, Ayis S, Peacock J, et al. Randomized trial of introduction of allergenic foods in breast-fed infants. N Engl J Med. (2016) 374:1733-43. doi: 10.1056/NEJMoa1514210

33. Du Toit G, Roberts G, Sayre PH, Bahnson HT, Radulovic S, Santos AF, et al. Randomized trial of peanut consumption in infants at risk for peanut allergy. N Engl J Med. (2015) 372:803-13. doi: 10.1056/NEJMoa14 14850

34. Obbagy JE, English LK, Wong YP, Butte NF, Dewey KG, Fleischer DM, et al. Complementary feeding and food allergy, atopic dermatitis/eczema, asthma, and allergic rhinitis: a systematic review. Am J Clin Nutr. (2019) 109:890S-934S. doi: 10.1093/ajcn/nqy220

35. Bellach J, Schwarz V, Ahrens B, Trendelenburg v, Aksünger Ö, Kalb B, et al. Randomized placebo-controlled trial of hen's egg consumption for primary prevention in infants. J Allergy Clin Immunol. (2017) 139:15919. doi: 10.1016/j.jaci.2016.06.045

36. Palmer DJ, Metcalfe J, Makrides M, Gold MS, Quinn P, West CE, et al. Early regular egg exposure in infants with eczema: a randomized controlled trial. J Allergy Clin Immunol. (2013) 132:387-92. doi: 10.1016/j.jaci.2013.05.002

37. Palmer DJ, Sullivan TR, Gold MS, Prescott SL, Makrides M. Randomized controlled trial of early regular egg intake to prevent egg allergy. J Allergy Clin Immunol. (2017) 139:1600-7.e2. doi: 10.1016/j.jaci.2016.06.052

38. Wei-Liang Tan J, Valerio C, Barnes EH, Turner PJ, van Asperen PA, Kakakios $\mathrm{AM}$, et al. A randomized trial of egg introduction from 4 months of age in infants at risk for egg allergy. J Allergy Clin Immunol. (2017) 139:16218.e8. doi: 10.1016/j.jaci.2016.08.035

39. Natsume O, Kabashima S, Nakazato J, Yamamoto-Hanada K, Narita M, Kondo $\mathrm{M}$, et al. Two-step egg introduction for prevention of egg allergy in high-risk infants with eczema (PETIT): a randomised, double-blind, placebo-controlled trial. Lancet. (2017) 389:276-86. doi: 10.1016/S0140-6736(16)31418-0

40. Nwaru BI, Takkinen HM, Niemela O, Kaila M, Erkkola M, Ahonen S, et al. Timing of infant feeding in relation to childhood asthma and allergic diseases. J Allergy Clin Immunol. (2013) 131:78-86. doi: 10.1016/j.jaci.2012.10.028

41. Hesselmar B, Saalman R, Rudin A, Adlerberth I, Wold A. Early fish introduction is associated with less eczema, but not sensitization, in infants. Acta Paediatr. (2010) 99:1861-7. doi: 10.1111/j.1651-2227.2010.01939.x

42. Papamichael MM, Shrestha SK, Itsiopoulos C, Erbas B. The role of fish intake on asthma in children: a meta-analysis of observational studies. Pediatr Allergy Immunol. (2018) 29:350-60. doi: 10.1111/pai.12889 
43. Saarinen KM, Juntunen-Backman K, Jarvenpaa AL, Kuitunen P, Lope L, Renlund M, et al. Supplementary feeding in maternity hospitals and the risk of cow's milk allergy: a prospective study of 6209 infants. J Allergy Clin Immunol. (1999) 104:457-61. doi: 10.1016/S0091-6749(99)70393-3

44. Katz Y, Rajuan N, Goldberg MR, Eisenberg E, Heyman E, Cohen A, et al. Early exposure to cow's milk protein is protective against $\operatorname{IgE}$ mediated cow's milk protein allergy. J Allergy Clin Immunol. (2010) 126:7782. doi: 10.1016/j.jaci.2010.04.020

45. Urashima M, Mezawa H, Okuyama M, Urashima T, Hirano D, Gocho N, et al. Primary prevention of cow's milk sensitization and food allergy by avoiding supplementation with cow's milk formula at birth: a randomized clinical trial. JAMA Pediatr. (2019) 173:1137-45. doi: 10.1001/jamapediatrics.2019.3544

46. World Health Organization. Breastfeeding. Available online at: http:// www.who.int/nutrition/topics/exclusive_breastfeeding/en/ (accessed April 7, 2020).

47. Muraro A, Halken S, Arshad SH, Beyer K, Dubois AEJ, Du Toit G, et al. EAACI food allergy and anaphylaxis guidelines. Primary prevention of food allergy. Allergy. (2014) 69:590-601. doi: 10.1111/all.12398

48. EFSA Panel on Dietetic Products, Nutrition and Allergies (NDA). Scientific Opinion on the appropriate age for introduction of complementary feeding of infants. EFSA J. (2009) 7:1423. doi: 10.2903/j.efsa.2009.1423

49. Turner PJ, Feeney M, Meyer R, Perkin MR, Fox AT. Implementing primary prevention of food allergy in infants: new BSACI guidance published. Clin Exp Allergy. (2018) 48:912-5. doi: 10.1111/cea.13218

50. Ruokolainen L, Paalanen L, Karkman A, Laatikainen T, von Hertzen L, Vlasoff $\mathrm{T}$, et al. Significant disparities in allergy prevalence and microbiota between the young people in Finnish and Russian Karelia. Clin Exp Allergy. (2017) 47:665-74. doi: 10.1111/cea.12895

51. Bridgman SL, Kozyrskyj AL, Scott JA, Becker AB, Azad MB. Gut microbiota and allergic disease in children. Ann Allergy Asthma Immunol. (2016) 116:99105. doi: 10.1016/j.anai.2015.10.001

52. Fujimura KE, Sitarik AR, Havstad S, Lin DL, Levan S, Fadrosh D, et al. Neonatal gut microbiota associates with childhood multisensitized atopy and T cell differentiation. Nat Med. (2016) 22:1187-91. doi: 10.1038/ nm.4176

53. Pretorius RA, Bodinier M, Prescott SL, Palmer DJ. Maternal fiber dietary intakes during pregnancy and infant allergic disease. Nutrients. (2019) 11:1767. doi: 10.3390/nu11081767

54. McKenzie C, Tan J, Macia L, Mackay CR. The nutrition-gut microbiomephysiology axis and allergic diseases. Immunol Rev. (2017) 278:27795. doi: 10.1111/imr.12556

55. Barachetti R, Villa E, Barbarini M. Weaning and complementary feeding in preterm infants: management, timing and health outcome. Pediatr Med Chir. (2017) 39:181. doi: 10.4081/pmc.2017.181

56. Cukrowska B. Microbial and nutritional programming-the importance of the microbiome and early exposure to potential food allergens in the development of allergies. Nutrients. (2018) 10:1541. doi: 10.3390/nu10101541

57. Yang I, Corwin EJ, Brennan PA, Jordan S, Murphy JR, Dunlop A. The infant microbiome: implications for infant health and neurocognitive development. Nurs Res. (2016) 65:76-88. doi: 10.1097/NNR.00000000000 00133
58. Moore RE, Townsend SD. Temporal development of the infant gut microbiome. Open Biol. (2019) 9:190128. doi: 10.1098/rsob.190128

59. Kumbhare SV, Patangia DVV, Patil RH, Shouche YS, Patil NP. Factors influencing the gut microbiome in children: from infancy to childhood. J Biosci. (2019) 44:49. doi: 10.1007/s12038-019-9860-Z

60. Bunyavanich S, Berin MC. Food allergy and the microbiome: current understandings and future directions. J Allergy Clin Immunol. (2019) 14:146877. doi: 10.1016/j.jaci.2019.10.019

61. Chernikova D, Yuan I, Shaker M. Prevention of allergy with diverse and healthy microbiota: an update. Curr Opin Pediatr. (2019) 31:41825. doi: 10.1097/MOP.0000000000000766

62. Chen CC, Chen KJ, Kong MS, Chang HJ, Huang JL. Alterations in the gut microbiotas of children with food sensitization in early life. Pediatr Allergy Immunol. (2016) 27:254-62. doi: 10.1111/pai.12522

63. Simonyte Sjodin K, Hammarstrom ML, Ryden P, Sjödin A, Hernell O, Engstrand L, et al. Temporal and long-term gut microbiota variation in allergic disease: A prospective study from infancy to school age. Allergy. (2019) 74:176-85. doi: 10.1111/all.13485

64. Venter C, Greenhawt M, Meyer RW, Agostoni C, Reese I, du Toit G, et al. EAACI position paper on diet diversity in pregnancy, infancy and childhood: novel concepts and implications for studies in allergy and asthma. Allergy. (2020) 75:497-523. doi: 10.1111/all.14051

65. Mohajeri MH, Brummer RJM, Rastall RA, Weersma RK, Harmsen HJM Faas $\mathrm{M}$, et al. The role of the microbiome for human health: from basic science to clinical applications. Eur J Nutr. (2018) 57(Suppl.):114. doi: 10.1007/s00394-018-1703-4

66. Zhang Z, Shi L, Pang W, Liu W, Li J, Wang H, et al. Dietary fiber intake regulates intestinal microflora and inhibits ovalbumin-induced allergic airway inflammation in a mouse model. PLoS One. (2016) 11:e0147778. doi: 10.1371/journal.pone.0147778

67. Miqdady M, Al Mistarihi J, Azaz A, Rawat D. Prebiotics in the infant microbiome: the past, present, and future. Pediatr Gastroenterol Hepatol Nutr. (2020) 23:1-14. doi: 10.5223/pghn.2020.23.1.1

68. Ly NP, Litonjua A, Gold DR, Celedón JC. Gut microbiota, probiotics, and vitamin D: interrelated exposures influencing allergy, asthma, and obesity? J Allergy Clin Immunol. (2011) 127:1087-94. doi: 10.1016/j.jaci.2011. 02.015

69. Sun J. Dietary vitamin D, vitamin D receptor, and microbiome. Curr Opin Clin Nutr Metab Care. (2018) 21:471-4. doi: 10.1097/MCO.0000000000000516

Conflict of Interest: The authors declare that the research was conducted in the absence of any commercial or financial relationships that could be construed as a potential conflict of interest.

Copyright (c) 2020 Ferrante, Carta, Montante, Notarbartolo, Corsello and Giuffrè This is an open-access article distributed under the terms of the Creative Commons Attribution License (CC BY). The use, distribution or reproduction in other forums is permitted, provided the original author(s) and the copyright owner(s) are credited and that the original publication in this journal is cited, in accordance with accepted academic practice. No use, distribution or reproduction is permitted which does not comply with these terms. 